\title{
ASPECTOS HISTÓRICOS DE LAS TRADUCCIONES Y TRADUCTORES DEL QUIJOTE EN ALEMANIA EN EL SIGLO XX
}

\author{
Javier García Albero \\ garciaalbero@hotmail.com \\ Universität Münster
}

\section{Resumen}

Afirmar que toda Alemania conoce el Quijote, que por todas partes circulan traducciones de la obra, no es nada nuevo. Que el lector medio sepa cuántas traducciones existen o cuándo se llevó a cabo la versión que está leyendo, es algo extraño. Y más extraño todavía es que el lector sepa quién ha sido el traductor, a no ser que se trate de los "traductores estrella" de la literatura alemana, en el caso del Quijote, Ludwig Tieck, en otros casos, por ejemplo, August Wilhelm Schlegel, Arthur Schopenauer, Walter Benjamin o Stefan Zweig. Pero junto a estas "estrellas" ha habido un sinnúmero de buenos traductores a los que no se ha prestado la atención que quizá merecen. Nuestro trabajo pretende recuperar algunos aspectos olvidados o no conocidos de las tres traducciones del Quijote que se realizaron en el siglo XX y, ante todo, de sus traductores. Ofreceremos con ello ciertos detalles interesantes sobre estos personajes y sobre las condiciones en que llevaron a cabo su labor.

\begin{abstract}
"Historical aspects of the translations and translators of Don Quixote in Germany in the 20 th century"

There is nothing new in saying that everyone in Germany knows Don Quixote, and that one can find translations of this work everywhere. But it is strange for the average reader to know how many translations there are or when the translation he is reading was done. And it is even stranger for the reader to know who the translator was if he is not one of the "star translators" of German literature, in the case of Don Quixote, Ludwig Tieck, in other cases for example August Wilhelm Schlegel, Arthur Schopenhauer, Walter Benjamin or Stefan Zweig. However, beyond these "stars" there
\end{abstract}


has been a large amount of good translators that have not been paid the attention they might deserve. This article tries to recover some forgotten or unknown details of the three German translations of the Quixote in the 20th century and, above all, of its translators. Some interesting details will be presented about these personalities and about the conditions under which they carried out their job.

Palabras clave: Historia. Traducción. Alemania. Quijote. Siglo XX.

Keywords: History. Translation. Germany. Quixote. 20th Century.

Manuscript received on May 15, 2012 and accepted on October 5, 2012. 


\section{Introducción}

Durante todo el siglo XX y lo que llevamos recorrido de este siglo XXI, la presencia del Quijote en Europa sigue el recorrido imparable iniciado ya con la aparición de la obra en 1605. Las tradicionales formas de recepción vienen complementadas por las nuevas formas de reexpresión de la obra capital de la literatura española: a la recepción en la crítica literaria y en los diferentes géneros literarios y artísticos se unen la televisión, el cine o Internet. No obstante, la principal forma de transmisión y recepción sigue siendo la traducción. Pese a la ingente cantidad de traducciones que nos dejó el siglo XIX, el siglo XX continuó con la labor traductora del Quijote, si bien es todavía mucho lo que queda por investigar de estas traducciones y de sus traductores. Repasando la bibliografía quijotesca se constata que los estudios cervantinos siguen centrándose ante todo en las traducciones del XIX, y, aunque no sin razón, por habernos legado este siglo las traducciones más exitosas y perdurables, no es menos cierto que bien merecen reconocimiento y agradecimiento los traductores que posteriormente emprendieron tamaña empresa y que, pese a no alcanzar las cotas de popularidad y fama de los anteriores, agrandaron la querencia de los lectores europeos por nuestra obra más universal. Así pues, este trabajo nace con el objetivo de escribir una página más en la historia de la traducción del Quijote, en un intento por arrojar luz sobre algunos puntos oscuros u olvidados de sus versiones alemanas en el siglo XX. Un volumen de historia de la traducción como este crea el marco perfecto para un trabajo como el nuestro, donde se presentan nuevos datos sobre las traducciones y, lo que más nos interesará aquí, sus traductores. La nueva historiografía de la traducción, nueva por ser un campo de estudio que está levantando el interés de investigadores de renombre en los últimos años, coincide en muchos casos -léanse los trabajos en este campo de Miguel Ángel Vega Cernuda ${ }^{1}$ (2008) o Anthony Pym (1998) — en que una historia de la traducción, imprescindible

1. Decía Vega que entre todos los factores que intervienen en el proceso de la traducción, "se trataría de primar la historia de los traductores en el contexto de la historia de la traducción" (Vega 2008: 140) 
para la correcta comprensión de la importancia de esta labor para la historia de la cultura, ha de escribirse comenzando por los traductores, sus actores principales. No sin razón comenzaba Louis Kelly su libro The true interpreter (1979) diciendo que son los traductores los artífices de la cultura occidental ("Western Europe ows its civilization to translators"). Este breve estudio no se propone ser más que un primer paso para un estudio histórico completo de las traducciones del Quijote en el siglo XX en Alemania. Este estudio de los cuadros personales y socioculturales de los traductores alemanes habrá de completarse en otros trabajos con un estudio de los textos si se quiere obtener un cuadro histórico completo.

Al igual que en Francia, donde la versión de Viardot se había consolidado como la traducción francesa por antonomasia, en Alemania siguieron editándose durante todo el siglo XX las traducciones convertidas en clásicas de Ludwig Tieck (1799-1801) y Ludwig Braunfels (1883). En un artículo aparecido hace pocos años se hacía un repaso a todas las ediciones del Quijote en el siglo XX alemán y en él hemos podido contar no menos de 32 ediciones diferentes del texto de Braunfels y no menos de 18 del de Tieck (Valero Cuadra 2007: 141-145). Junto a éstas, la gran mayoría, aparecían también ediciones del traductor ilustrado Dietrich Wilhelm Soltau (1800-1801), de la edición revisada de Ernst von Wolzogen (1893) y algunas ediciones de las tres traducciones realizadas en esta centuria, a las que nos dedicaremos en las siguientes páginas.

\section{Felix P. Greve, alias Konrad Thorer: la traducción frenética por necesidades pecuniarias}

En 1908 se publica en la prestigiosa editorial Insel Verlag una nueva traducción del Quijote. En su primera edición se indica, como puede verse en la bibliografía al final de este artículo, que la traducción es obra de Konrad Thorer y que para ella se ha servido de la edición anónima de 1837, traducción indirecta realizada a partir de una versión francesa que se había publicado con el famoso prólogo de Heinrich Heine. Sin embargo, la traducción era en realidad más una reelaboración y revisión de la traducción de 1837 que una traducción independiente y, por ello, en las ediciones posteriores se modificaron los créditos de autoría de la traducción para especificar que se trata de una revisión del texto de 1837 por parte de Thorer. Esta traducción-revisión vio algunas reediciones a lo largo del siglo, apareciendo siempre el nombre de Konrad Thorer como traductor o revisor del texto. Lo cierto es que Konrad Thorer no es más que un pseudónimo que ha venido perpetuándose como si de persona real se tratase. El traductor real que se escondía bajo ese nombre 
fue Felix Paul Greve, un curioso caso de escritor que se escondía bajo numerosos pseudónimos y que, pese a haberse descubierto hace ya algunos años su identidad, sigue sin aparecer en muchos estudios más que con sus diversos pseudónimos. Que se haya dado hasta el momento tan poca importancia al papel del traductor, y mucha menor a la de los editores o revisores, ha llevado a que durante décadas se haya reproducido y se siga reproduciendo el pseudónimo Konrad Thorer como autor de la revisión del texto de 1908.

Como acabamos de mencionar, nos encontramos ante un caso curioso de escritor oculto bajo diferentes nombres. Felix Paul Greve (1879-1948) ${ }^{2}$ nació en territorio prusiano, en Radomno, la actual Polonia, donde pasó los primeros años de su vida. Desde allí, la familia se trasladó a Hamburgo, donde Greve se formó en los mejores centros de secundaria de la ciudad hasta que decidió estudiar Filología Clásica y Arqueología en Bonn. Sin haber terminado los estudios, pasó una temporada en Italia y después en Múnich, donde entró en los círculos literarios más importantes de la época y estuvo en contacto con Stefan George, Karl Wolfskehl o Thomas Mann. Ya durante sus años escolares había sobresalido Greve por su inteligencia, aunque también por su afán de ascenso social, que le llevó a tener que pedir grandes sumas de dinero para poder permitirse el tren de vida que deseaba. Encontró su mecenas particular en un viejo amigo de la escuela, Herman F. C. Kilian, quien pocos años después y ante la gran cantidad de dinero que se le adeudaba, decidió denunciar a Greve, tras lo cual éste hubo de pasar un año en prisión por las sumas que no había devuelto a Kilian y a otros acreedores. Ahogado por su situación económica, Greve comenzó una frenética labor traductora para intentar pagar sus deudas; fueron años de acumulación de traducciones e incluso de producción de obras propias, pues llegó a publicar dos novelas: Fanny Essler (1905) y Maurermeister Ihles Haus (1906). Es en este contexto en el que Greve publica su traducción del Quijote, que como hemos dicho fue más una revisión de un texto anterior que una traducción propia. No obstante, sería interesante un estudio crítico de la traducción, tanto del Quijote como de las Novelas ejemplares, para ver hasta qué punto se descubre la pluma de Greve en los textos, algo que, por lo que sabemos, nadie ha realizado hasta el momento.

Como decíamos, Felix Paul Greve, alias Konrad Thorer, publicó la traducción-revisión del Quijote en 1908, pero son muchas más las traducciones

2. La vinculación de Felix Paul Greve con sus diferentes pseudónimos y su nueva identidad en Canadá fue descubierta en 1973 por D. O. Spettigue. La mayor parte de los datos biográficos que aquí ofrecemos pueden encontrarse en la obra de Klaus Martens que citamos en la bibliografía, centrada sobre todo en sus años en Alemania, en los cuales llevó a cabo su labor traductora. 
que llevó a cabo, siempre de grandes escritores ingleses, franceses, italianos y españoles: en su nómina de traducidos se encuentran Honoré de Balzac (Eine dunkle Begebenheit, etc.), Alejandro Dumas padre (Der Graf von Monte Cristo), Gustave Flaubert (Bouvard et Pécuchet, etc.), André Gide (Die enge Pforte, etc.), Alain René de Lesage (Gil Blas), Dante Alighieri (sonetos de Vita Nuova), Charles Dickens (David Copperfield), Jonathan Swift (Prosaschriften) y Oscar Wilde (Das Bildnis Dorian Grays), entre muchos otros. De Cervantes tradujo además, como decíamos, las Novelas Ejemplares (Die Novellen des Cervantes, 1907). La labor traductora de Greve es digna de mención y estudio. Su inmenso trabajo de versión al alemán se produjo en tan sólo unos pocos años, a finales del XIX y principios del XX, antes de que su situación económica resultara tan insostenible que Greve se viera forzado a abandonar el país y emigrar a América. Pero no fue esta huida una emigración cualquiera: Greve fingió su propia muerte en 1909 y pasó a los Estados Unidos, donde adoptó el nombre de Frederick Philip Grove. Desde allí pasó a Canadá, donde comenzó a impartir clases en diversos colegios y donde poco más tarde inició una carrera literaria... ¡ ien inglés! Las obras de Greve se convirtieron rápidamente en grandes éxitos de ventas y son todavía muy apreciadas por la crítica. Greve /Grove pasó a ser uno de los primeros clásicos de la literatura canadiense: obras como Over Prairie Trails (1922), The turn of the Year (1923) o las presuntas obras autobiográficas A Search for America (1927) e In Search of Myself (1946) entraron a formar parte del canon canadiense y a estudiarse en escuelas y universidades. Las dos últimas obras, decíamos, son presuntamente autobiográficas. Greve se presentaba como un inmigrante nacido en Europa que había recorrido medio mundo, pero no como alemán, sino como procedente de Suecia. La confusión que creó con estos relatos llegó a crear un halo misterioso alrededor de su persona que no se descubrió hasta muchos años después de su muerte. Así pues, el caso de Greve es absolutamente excepcional: es el caso de un autor-traductor que consigue hacer dos carreras literarias en dos países diferentes, bajo dos nombres diferentes y en dos lenguas diferentes. Hasta qué punto influyó en su carrera literaria su frenética labor traductora podría ser un buen estudio futuro. Como se sabe, muchos fueron los escritores que consideraban la traducción como un paso previo a la propia escritura, un ejercicio formativo con el cual aprender a dominar la propia lengua. ${ }^{3}$

3. Nos viene a la memoria el ejemplo de Stefan Zweig, quien en aquella misma época opinaba que la traducción es el paso previo para una futura carrera literaria. Zweig comenzó traduciendo a Emile Verhaeren y, siguiendo el consejo del escritor Richard Dehmel, antes de comenzar su exitosa carrera literaria tradujo a Baudelaire, Verlaine, Keats, Lemonnier... (cf. García Albero 2008). 


\section{Roland Schacht y el Quijote olvidado}

Tras Greve, pasarían bastantes años hasta que otro amante de la literatura retomara las fatigas de traducir a la lengua alemana al genio alcalaíno. El siguiente traductor es con seguridad el más olvidado y obviado de los traductores alemanes del Quijote: Roland Schacht. De hecho, rara es la vez en que aparece su nombre en la bibliografía cervantina, como si nunca hubiera llevado a cabo el trabajo de versar la obra de Cervantes, de la que además de traducir el Quijote hizo lo propio con las Novelas Ejemplares. ${ }^{4}$ Roland E. A. Schacht, hijo de los actores Eduard y Mathilde Schacht, nació en 1888 en Reicheneberg, la actual Liberec checa. Tras sus estudios de Filología Germánica, Lenguas Modernas e Historia del Arte en diferentes universidades (Gotinga, París, Berlín y Múnich), se doctoró con 22 años con una tesis sobre la evolución de la tragedia: Die Entwicklung der Tragödie in Theorie und Praxis von Gottsched bis Lessing (1910). A partir de ese momento, se dedicó a escribir en diferentes periódicos y revistas como crítico de cine, teatro y literatura. En el ámbito teatral y cinematográfico es donde más huella dejó y sus crónicas y críticas siguen citándose hoy en día. Además de como crítico, Schacht destacó como autor de piezas teatrales y de guiones para películas. En el cine, basta un vistazo a una base de datos cinematográfica ${ }^{5}$ para ver su participación en diferentes largometrajes de los años 30 y 40. De los éxitos teatrales que cosechó con sus propias composiciones nos da una idea la necrología que apareció en el diario Der Tagesspiegel el 29 de septiembre de 1961, justo una semana después de su muerte. Allí se citaban las piezas por las que se le recordaría en la escena berlinesa: Mama räumt auf; Christine von Schweden; Schauspielerin; Zum Glück gehört Charakter... Tras el período dedicado al teatro, Schacht se dedicó a la literatura. Además de redactar algunas obras (destaca en este apartado Aufstand der Asketen, 1955, donde satiriza el milagro económico alemán), tradujo numerosas obras tanto del español (Cervantes) como del inglés (William J. Blake, Maria Meinhardt. Roman aus dem amerikanischen Bürgerkrieg) y, sobre todo, del francés (Guy de Maupassant, Pierre und Jean; Robert Antelme, Die Gattung Mensch; Gabriel Chevallier, Clochemerle-Babylon; etc.).

Las Novelas aparecieron en la editorial Rütten und Loening de Potsdam en 1948, aunque sabemos que esta tarea la llevó a cabo durante los años de la guerra. El que esto suscribe descubrió hace algún tiempo una serie de documentos en los archivos de la Akademie der Künste de Berlín —concretamente en los

4. Miguel de Cervantes. (1948) Muster-Novellen. Potsdam: Rütten \& Loening. 2 vols.

5. La más completa a disposición del público general es seguramente la base de datos en Internet IMDB (www.imdb.com) 
archivos de Eduard Schacht y de Walther von Molo-, en los que se encuentran algunas cartas de Schacht junto con recortes de periódicos, documentos biográficos, fotografías, etc. En una de estas cartas, dirigida a Walther von Molo y fechada a 18 de diciembre de 1944, escribía Schacht que se encontraba traduciendo, en el Berlín de los días más crueles de la guerra, las Novelas de Cervantes:

(...) habe aber fleißig an meinen Übersetzungsaufträgen geschafft, (...) (Manzoni, Gullivers Reisen...) und einen großen Teil der Musternovellen von Cervantes. Letztere enthalten äußerst merkwürdige Sachen. Ich weiß nicht, ob Sie sie kennen. Leider ist das Spanisch wegen vieler Rotwelschausdrücke sehr schwierig, zumal die spanischen Kommentare zu diesen Dingen nicht $z u$ beschaffen sind. ${ }^{6}$

Por lo que leemos aquí, se encontraba traduciendo alguna obra del italiano Alessandro Manzoni y los Viajes de Gulliver, obras que no aparecen en los catálogos junto a su nombre, por lo que podemos pensar que se publicaron sin hacer referencia al traductor.

Poco después, en una carta al mismo destinatario fechada a 16 de febrero de 1945 confirmaba "die Cervantes-Novellen sind fertig". En nuestra humilde opinión, es digno de loa que en días tan crueles como los vividos en la Alemania de la II Guerra Mundial, que sufría a diario los bombardeos aliados, un espíritu como el de Schacht se dedicara a las letras españolas, a la versión de las obras de Cervantes, con la carencia de recursos que bien podemos imaginar y de la que se lamentaba en la carta anteriormente citada. Pero no solo la traducción de las Novelas proporcionaba cierto consuelo a Schacht en días tan duros. Por otra carta sabemos que también fue durante la guerra cuando se dedicó a revisar su traducción del Quijote, que había llevado a cabo años antes, según entendemos por la misiva, dirigida también a von Molo y fechada a 7 de enero de 1944:

Zum eigentlichen Arbeiten ist kaum Gelegenheit. Irgendwann werde ich mich doch einmal entschließen müssen, die Eindrücke des letzten Jahres in einer größeren Arbeit zu gestalten, im Augenblick beschäftige ich mich sozusagen mit Kunstgewerbe, d.h. ich revidiere, allerdings mit eigenem Vergnügen, eine alte Übersetzung von Don Quijote. ${ }^{7}$

6. (...) pero he seguido trabajando con diligencia en mis encargos de traducción, (...) (Manzoni, Los viajes de Gulliver...) y en una gran parte de las Novelas ejemplares de Cervantes. Estas últimas contienen cosas muy curiosas. No sé si ya las conoce Vd. Por desgracia, el español es muy complicado por las muchas expresiones del lenguaje de germanías, y además los comentarios españoles sobre estas cuestiones son imposibles de encontrar. [Mi traducción]

7. Casi no tengo ocasión de ponerme al trabajo real. Alguna vez tendré que decidirme a redactar las impresiones del último año en un trabajo más extenso; ahora mismo me 
Esta traducción tendría que esperar todavía algunos años para ser publicada. No fue hasta 1951 cuando la misma editorial Rütten \& Loening sacara a la luz la traducción en dos tomos, con una presentación inmejorable para la época que corría, con la carencia de papel que tanto angustiaba a autores y editores.

Sólo hay que lamentar que Schacht no redactara sus vivencias, como le hubiera gustado si atendemos a lo dicho en la carta anterior a von Molo. Tampoco en su traducción escribió ningún prefacio ni nota que nos dé una idea de las vicisitudes del traductor en su tarea ni de la concepción que tenía de la obra. Sí podemos saber que, como a muchos otros traductores, el Quijote le parecía quizá demasiado largo y que algunas partes — suponemos que se refiere a las novelas intercaladas- podrían haberse eliminado. Deducimos e interpretamos todo ello de una carta que dirigió el 21 de marzo de 1955 al mismo Walther von Molo:

(...) aber ich glaube nicht recht an dicke Bücher und bin der inneren Überzeugung, da $\beta$ alles was räumlich über die Länge eines platonischen Dialogs hinausgeht, im Gründe überflüssig ist. Selbst der Don Quijote (haben Sie eigentlich meine Übersetzung bekommen?) und die Ilias könnten durch Konzentrierung gewinnen. ${ }^{8}$

En ese mismo año apareció la segunda edición de la traducción de Schacht, la que podríamos denominar la primera traducción quijotesca de la RDA, pese a que el traductor ya había abandonado el sector oriental de Berlín y huido al Oeste (Huchel 1995: 229). Por la edición deducimos la significación otorgada a la obra en una editorial que por aquel entonces ya había pasado a manos del Gobierno socialista del partido unificado SED. En 1950 el partido había requisado la editorial y la había puesto en manos del Holding de la SED "Zentrag" (Zentrale Druckerei-, Einkaufs- und Revisionsgesellschaft), un órgano en que se concentraba toda la industria impresora y editorial de la recién creada república socialista. Decíamos que la de Schacht era la primera traducción quijotesca de la RDA, pues no fue la única que allí se imprimió. Junto a ésta, se siguieron publicando las de Tieck y Braunfels en diferentes editoriales de la RDA. Hemos contado 9 ediciones en el inventario que hacía Valero Cuadra en editoriales diferentes: de la traducción de Tieck en el Kinderbuch Verlag de Berlín en 1979 y 1981; en la editorial Reclam en 1987; y en la misma en

mantengo ocupado con, digamos, ocupaciones artesanas, esto es, estoy revisando, por supuesto con gran gusto, una vieja traducción del Don Quijote. [Mi traducción]

8. (...) pero no acabo de creer en libros voluminosos y estoy convencido de que todo lo que ocupe más espacio que un diálogo platónico es en principio superfluo. Incluso el Don Quijote (por cierto ¿ha recibido Vd. mi traducción?) y la Ilíada podrían salir ganando si se llevara a cabo una concentración. [Traducción mía] 
que había aparecido la de Schacht, Rütten \& Loening, en 1982, 1984 y 1986; y la traducción de Braunfels en la editorial Verlag Neues Leben en 1985, 1988 y 1990. Nos damos cuenta con este recuento de que desde 1955, año de la segunda edición de Schacht, hasta 1979, en que se reedita la de Tieck, hay un periodo de casi 25 años en que no se ofrece el Quijote al público lector de la Alemania Oriental. Tras ese cuarto de siglo, hasta la reunificación de Alemania las ediciones se acumularán con una frecuencia de aparición casi anual.

También cabría resaltar que la traducción de Schacht apareció acompañada de ilustraciones, dibujos a pluma, del artista Josef Hegenbarth (18841962), el cual, nacido en Bohemia y residente en la ciudad sajona de Dresde, donde pasó la mayor parte de su vida, fue uno de los más notables dibujantes e ilustradores del siglo XX en Alemania. La imagen iconográfica de don Quijote y Sancho en Hegenbarth es, por cuanto sabemos, algo completamente desconocido y hasta ahora no se han recogido sus ilustraciones en los bancos de imágenes existentes del Quijote. ${ }^{9}$

\section{Un Quijote con tintes austríacos: la traducción de Anton Maria Rothbauer}

Tras Schacht, aparecería la traducción de mayor repercusión de las realizadas en el siglo XX, la traducción de Anton Maria Rothbauer (1905-1971). Pese a ser un conocido traductor y un hombre público, puesto que Rothbauer fue profesor de literatura española en la universidad austríaca de Graz, muchas son las lagunas que quedan en la biografía de este humanista. ${ }^{10}$ Nacido el 25 de enero de 1905 en Taufkirchen an der Pram, un pequeño pueblo cerca de la frontera con Alemania, este hijo de maestro cervecero pasó su infancia, debido al trabajo de su padre, en Eggenberg, actualmente un distrito de la capital de Estiria, Graz. Al parecer, aprendió el oficio de cerrajero y se supone que realizó trabajos en este sector, pues no se han conservado datos de su actividad hasta que en 1938, con la anexión de Austria por parte de la Alemania hitleriana, tuvo que huir del país e instalarse en Francia, mientras que su esposa e hija se exiliaban a Inglaterra. En Francia estuvo encarcelado hasta la ocupación del país por Alemania en 1940, momento en el que Rothbauer aprovechó para escapar a España, donde pasó los siguientes años. Esta estancia

9. Hemos consultado el "Banco de Imágenes del Quijote" (www.qbi2005.com), que presenta 550 ediciones y 17603 imágenes, y la base de datos de "Iconografía textual del Quijote" (http: //dqi.tamu.edu), que ofrece 38.012 ilustraciones de 703 ediciones, según anuncian en las respectivas páginas web.

10. Esto mismo lo expresa en su artículo Sepp Färber (1991), artículo del cual hemos extraído la mayor parte de los datos biográficos que aquí se ofrecen. 
en España, posiblemente en Barcelona, le llevó a ser un gran conocedor de la lengua española y de su literatura. Tras la guerra, regresó a Austria y se estableció en la ciudad de Graz, en cuya universidad comenzó en 1947 a impartir lecciones de español y de literatura española en el Instituto de Formación de Intérpretes (Institut für Dolmetschausbildung). Que los datos biográficos de que se dispone sobre este traductor son escasos lo demuestra la misma página web de esta institución, el actual "Institut für Theoretische und Angewandte Translationswissenschaft", en una de cuyas secciones aparecen los nombres de personajes ilustres. Por supuesto, aparece el nombre de nuestro traductor, pero el enlace que debería llevarnos a sus datos biográficos, como sucede con las otras personalidades que allí se presentan, no está conectado a ninguna página vinculada. ${ }^{11}$ Sea como fuere la biografía prebélica de este traductor, su actividad docente, investigadora y traductora posterior a la guerra nos muestra algunos detalles dignos de mención. Rothbauer se doctoró en 1953 con una tesis sobre Antonio Machado, del cual tradujo casi simultáneamente algunas poesías para un volumen misceláneo de poesía internacional. ${ }^{12}$ También tradujo obras menores del francés (Die Schwäche Gottes, de Jean Sulivan, y Der gottesfürchtige Grobschmied, de Sylvain Roche) y del inglés (Spanien - Mythos und Wirklichkeit, de Richard Pattee). Esta última traducción del original This Is Spain es un caso curioso de traducción, pues al más puro estilo de las bellas infieles Rothbauer modifica, complementa y amplía el original, tal como explica en el prefacio del libro:

(...) da ich den ursprünglichen Text, wenn auch im Sinne Pattees, doch auf eigene Verantwortung für das Verständnis im deutschen Sprachgebiet bearbeitet und aus eigenem Material ergänzt habe. (Cit. en Färber 1991: 102) ${ }^{13}$

La intención de Rothbauer no era otra que la de ofrecer una imagen más completa de España, un país que admiraba y que en aquellos momentos, con la dictadura de Franco en su apogeo, era vista con recelo en la escena internacional. Más allá de lo político, Rothbauer pretendía mostrar las bondades de un país que le había acogido, cuya literatura apreciaba y que quería mostrar en su país natal desvestido de tintes políticos. En este sentido, el mayor favor que pudo hacerle Rothbauer a España y su literatura fue su dedicación a la

11. La página fue consultada por última vez el 10 de mayo de 2012 (http: //www.uni-graz. at/uedolwww/uedolwww_institut/uedolwww_institut_geschichte.htm)

12. Braun, Felix (1952) Die Lyra des Orpheus: Lyrik der Völker in deutscher Nachdichtung. Viena: P. Zsolnay

13. (...) pues aunque he mantenido el sentido de Pattee, bajo mi propia responsabilidad he reelaborado el texto original y lo he complementado con material propio para una mejor comprensión en el ámbito lingüístico alemán. 
traducción del español al alemán. La primera obra de calado que versó fue el Tirano Banderas de Valle-Inclán (Tyrann Banderas, 1961), que además de situar al autor en el primer plano del mapa literario y traductor de su país, nos deja reflexiones interesantes sobre la concepción traductológica del mismo. Así, ante la dicotomía schleiermacheriana de acercamiento del lector al texto original o del original al lector meta, Rothbauer se decanta por la primera opción:

Unsere Übertragungen, auch die besten, gehen von einem falschen Grundsatz aus: sie wollen das Indische, Griechische, Englische verdeutschen, anstatt das Deutsche zu verindischen, vergriechischen, verenglischen. Sie haben eine viel bedeutendere Ehrfurcht vor den eigenen Sprachgebräuchen als vor dem Geist des fremden Werks. (Cit en Färber 1991: 104)14

Además de traducir a Machado y a Valle Inclán, Rothbauer se ocupó de versar la obra del chileno Manuel Rojas Hijo de ladrón (publicada en 1955 con el título Wartet, ich komme mit en Graz y como Der Sohn des Diebes en 1967 en la RDA) y de traducir y adaptar a la escena algunas obras de dramaturgos españoles, como Calderón. Pero sin duda la obra de su vida y la que más nos interesa aquí es su traducción de las obras completas de Cervantes, siendo el primero en llevar a cabo esta tarea y en presentar al público alemán textos cervantinos hasta el momento desconocidos en su lengua. La traducción apareció en cuatro tomos entre los años 1963 y 1970. El segundo volumen (1964) recoge la traducción de las dos partes del Quijote, una traducción elogiada en un principio por la crítica pero que, pese a ello, se ha visto editada en menor medida que otras versiones anteriores con las que tuvo que competir, tales como las de Tieck o Braunfels, sin duda más apetitosas para los editores por no tener que abonar éstos derechos de autor por sus textos.

Las críticas a la traducción, como anunciábamos, fueron en un primer momento elogiosas, como la de Lorenz,$^{15}$ aparecida en Die Welt der Literatur y que citamos en nuestra bibliografía. Mas también es verdad que hubo opiniones contrarias a su versión, un texto en el que el traductor había introducido algunos austriacismos y en el que, tras un examen detallado, pueden

14. Nuestras traducciones, incluso las mejores, parten de una premisa equivocada: pretenden alemanizar lo indio, lo griego, lo inglés, en lugar de dar a lo alemán un carácter indio, griego o inglés. Sienten una veneración mucho más significativa por los usos lingüísticos propios que por el espíritu de la obra extranjera. [Mi traducción]

15. Wir wissen nicht, welches Bild sich ein kommendes Jahrhundert von Cervantes machen wird, aber wir wissen, daß fortan kein Weg mehr an Rothbauer vorbeiführen wird, vorbeiführen kann (...) [No sabemos qué imagen de Cervantes se construirá el siglo venidero, pero sí sabemos que en adelante ningún camino esquivará ni podrá esquivar a Rothbauer (...)] (Lorenz 1970: 11) 
encontrarse errores. ${ }^{16}$ Sea como fuere, pues no es nuestro cometido en este trabajo llevar a cabo una crítica de las traducciones del Quijote, cabe decir que el trabajo de Rothbauer es una traducción filológica que toma como base la edición de Rodríguez Marín y que ofrece una introducción del traductor y un aparato crítico de notas en las que, además de expresar el significado original de locuciones, expresiones y presuposiciones, también justifica algunas de sus traducciones y las compara con traducciones anteriores. De hecho, Rothbauer las conocía bien, sobre todo la de Tieck, que había analizado y en la que había contabilizado no menos de, en su opinión, 4000 errores. ${ }^{17}$ Pese a ello, pese a los errores que pueda tener la traducción de Tieck y pese a los conocimientos traductológicos que tuvo Rothbauer, la versión de éste nunca ha podido imponerse a la del romántico, lo cual nos debería hacer pensar en los diversos factores que hacen que una traducción se imponga entre otras como la traducción clásica de una obra, factores entre los que la fidelidad al original puede ser algo secundario. De hecho, uno de los puntos de crítica de Rothbauer a sus antecesores fue la traducción de la colocación "el caballero de la triste figura", una frase que había pasado a la tradición alemana como "der Ritter von der traurigen Gestalt" y que el de Graz quiso corregir traduciéndola por "der Ritter mit dem kläglichen Gesicht", que puede que sea filológicamente más fiel pero que rompe con una tradición que el lector, habituado a la colocación del "traurigen Gestalt" recibe como extraña y no acepta.

\section{Conclusiones}

En este artículo, sin entrar a valorar la calidad de las versiones o su grado de dependencia de otras traducciones anteriores, lo cual dejamos para trabajos de crítica traductora posteriores, hemos situado en un primer plano el contexto que rodeó su aparición y el perfil de los traductores que las realizaron, aspectos que deberían, en nuestra opinión, tomarse muy en cuenta a la hora de realizar el análisis crítico. Así, hemos visto que la primera versión

16. Véase, por ejemplo, la recensión aparecida en 1967 en Die Zeit y que añadimos a nuestra bibliografía. Allí criticaba el autor del artículo duramente la traducción y al traductor: "Soll der Maßstab einer guten Übersetzung ihre Fehlerlosigkeit sein, so ist seine eigene schlecht, und zwar schlechter als das Deutsch seiner Einführungen und Kommentare" [Si el listón de una buena traducción es su carencia de errores, la suya propia es, en cambio, mala, e incluso peor que el alemán de sus introducciones y comentarios]

17. Rothbauer redactó en 1962 una separata a su edición de las obras completas de Cervantes titulada Der unbekannte Cervantes (El Cervantes desconocido), en la que afirmaba haber encontrado un sinnúmero de errores por falta de conocimientos de español de los traductores anteriores. Esta separata constituyó una ácida crítica a la traducción de Tieck, atribuyéndole nada menos que 4000 errores (Rothabuer 1962: 19) 
aparecida en el siglo XX fue obra de un incansable traductor, Felix Paul Greve, que, tanto por propio gusto como por necesidades económicas, se dedicó a versar y revisar grandes obras de la literatura universal al alemán, entre ellas el Quijote y las Novelas ejemplares de Cervantes. La traducción es en su caso un medio de subsistencia, pero sin duda también un medio formativo para el dominio de lenguas y literaturas que le permitiría más tarde labrarse una carrera literaria nada menos que en dos lenguas diferentes. El segundo de nuestros traductores, Roland Schacht, es un traductor olvidado, tanto por la crítica como por la historia. No hemos entrado en valoraciones sobre sus versiones cervantinas, simplemente el pensar que pudiera estar dedicándose a esta noble tarea en días tan duros como los de la II Guerra Mundial en el Berlín asediado por los bombardeos lo hace digno de nuestra admiración. La traducción como vía de escape del desastre, como oasis en medio del desierto, las bellas letras como consuelo en días tan inhumanos, Roland Schacht como el traductor que encontró en Cervantes el alivio a la crudeza y cuya traducción publicó en sus primeros años de vida la RDA: todo ello nos parece muy digno de mención y nos sorprende que hasta ahora nadie lo haya hecho, seguramente por la indiferencia hacia los traductores "de segunda fila" que se ha vivido durante siglos.

Finalmente, encontramos en Anton M. Rothbauer a un nuevo traductor que encomendándose a San Jerónimo, de quien tenía una figura esculpida por él mismo en su escritorio, nos ofreció con su versión de las obras completas de Cervantes el último testimonio traductor quijotesco del siglo XX en tierras germanas. El éxito o el fracaso, la calidad o no de cada una de estas traducciones, es caso aparte. Lo importante para nosotros es que todas hicieron historia, todas acrecentaron la historia de nuestra obra más universal, y así las hemos querido recordar aquí.

\section{Bibliografía}

Baumann, Hans-Heinrich. (1967) "Der Erfinder des Herrn Quijote." Die Zeit 47, 24. November 1967, pp. 9.

Cervantes SaAvedra, Miguel de. (1908 -translation-) Don Quixote. Unter Benutzung der anonymen Übertragung von 1837 übersetzt von Konrad Thorer. Drei Bände. Einleitung von Felix Poppenberg. Frankfurt a.M.: Insel Verlag. [En adelante publicado por la misma editorial como Der scharfsinnige Ritter Don Quixote von der Mancha. Textrevision nach der anonymen Ausgabe 1837 von Konrad Thorer] 
Cervantes SAAVEdRa, Miguel de. (1951 -translation-) Leben und Taten des scharfsinnigen Edlen Don Quijote von La Mancha. Übersetzt von Roland Schacht. 268 Tuschzeichnungen von Josef Hegenbarth. 2 Bände. Potsdam: Rütten \& Loening. CERVANTES SAAVEdRA, Miguel de. (1964 -translation-) Der scharfsinnige Edle Herr Don Quijote de la Mancha. Herausgegeben und neu übersetzt von Anton M. Rothbauer. Tomo II de Gesamtausgabe in vier Bänden. Stuttgart: Henry Goverts Verlag.

FÄrber, Sepp. (1991) “Anton Maria Rothbauer als Übersetzer.” En: Canticum Ibericum: neuere spanische, portugiesische und lateinamerikanische Literatur im Spiegel von Interpretation und Übersetzung. Frankfurt a.M.: Vervuert, pp. 99-110.

GANSEL, Carsten. (1996) Parlament des Geistes. Literatur zwischen Hoffnung und Repression 1945-1961. Berlin: BasisDruck Verlag.

GARCíA Albero, Javier (2008) "Stefan Zweig, traductor." En: Navarro, Fernando et al. (eds.) La traducción: balance del pasado y retos del futuro. Alicante: Univ. Alicante, pp. 421-430

LoREnZ, Günther W. (1970) "Miguel de Cervantes oder die deutsche Neugeburt eines Dichters.” Die Welt der Literatur, Nr. 2, 22. Januar 1970, pp.10-11.

MarTens, Klaus. (1997) Felix Paul Greves Karriere. Frederick Philip Grove in Deutschland. St. Ingbert: Röhrig Universitätsverlag.

Nijssen, Hub. (1995) Der heimliche König. Leben und Werk von Peter Huchel. Nijmegen: Universiteitdrukkerij.

PyM, Anthony. (1998) Method in Translation History. Manchester: St. Jerome Publishing.

Rothbauer, Anton M. (1956) "Zum Problem des literarischen Übersetzens." Lebende Sprachen 2/3, pp. 86-89.

Rothbauer, Anton M. (1962) Der unbekannte Cervantes. Sonderdruck. Stuttgart: Henry Goverts Verlag.

SCHACHT, Roland. (1926) "Soll man die Bibel neu übersetzen?" Die literarische Welt 2, 21/22, Februar 1926, p.165.

VAlero CuAdra, Pino. (2007) "Traducciones alemanas de El Quijote (1907-2007): notas para una traducción del siglo XX." En: Navarro Domínguez, Fernando y Miguel Ángel Vega Cernuda (eds.) 2007. España en Europa: la recepción de El Quijote. Alicante: Universidad de Alicante, pp. 139-150.

Varios autores (1964) “Cervantes. Schöne Wunden”. Der Spiegel 13, pp.105-109. Vega Cernuda, Miguel Ángel. (2008) "La historia de la traducción como tarea de investigación de las letras costarricenses". Letras 43, pp.125-142. 


\section{NOTA BIOGRÁFICA / BIONOTE}

Javier García Albero es licenciado en Traducción e Interpretación por la Universidad de Alicante. Completó sus estudios en la Universidad Paris-Lodron de Salzburgo. Comenzó el doctorado en Traducción de la Universidad de Alicante, obteniendo el Diploma de Estudios Avanzados gracias a una beca del DAAD para investigar en la Universidad de Münster (Alemania). Entre 2008 y 2010 trabajó como profesor asociado en el Departamento de Traducción de la Universidad de Alicante. Desde 2010 es lector de español en la Universidad de Münster (Alemania). Ha participado en diferentes congresos en España, Alemania y Costa Rica.

Javier García Albero holds a degree in Translation and Interpreting from the University of Alicante. He completed his studies at the Paris-Lodron University of Salzburg. He started his PhD studies on Translation at the University of Alicante and was awarded the Diploma of Advanced Studies thanks to a grant from the DAAD which enabled him to do research at the University of Münster (Germany). Between 2008 and 2010 he worked as an adjunct professor at the Department of Translation of the University of Alicante. Since 2010 he teaches Spanish at the University of Münster. He has participated in different conferences in Spain, Germany and Costa Rica. 